\title{
Directed Palladation: Fine Tuning Permits the Catalytic 2-Alkenylation of Indols
}

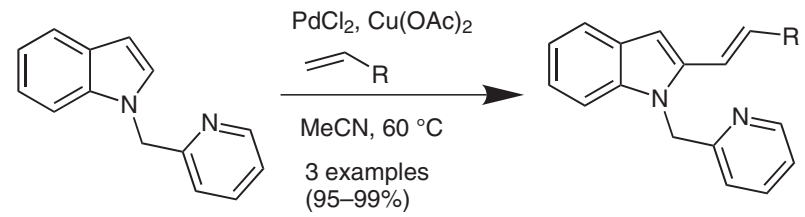

Significance: The synthesis of 2-vinyl indoles by a $\mathrm{Pd}$-catalyzed $\mathrm{C}-\mathrm{H}$ activation process induced by coordination from a $\mathrm{N}$-picolinyl is described. By testing several different $\mathrm{N}$-substituents e.g. oxazolino methyl, dimethylcarbamoyl, and allylmethylcarbamoyl, the picolinyl group is shown to be optimal for the $\mathrm{C}-\mathrm{H}$ activation of the indole 2-position. In the three examples given $\left(\mathrm{R}=\mathrm{CO}_{2} \mathrm{Me}\right.$, $\mathrm{SO}_{2} \mathrm{Ph}$ and $\mathrm{CN}$ ), the reactions proceed in almost quantitative yields. Although not indicated, the starting substrate may be easily prepared (T. Guengoer, P. Malabre, J. Teulon Synth. Commun. 1994, 24, 2247).
Comment: 2-Vinyl or 2-styryl indoles are usually obtained from 2-prefunctionalized derivatives or, recently, by Pd-catalyzed Heck or cross coupling reactions of corresponding halide or boronic acid intermediates. This procedure, if generalized and tested for functional group tolerance, will provide an oxidative Heck route to 2-substituted indoles. The 2-alkenyl substituted indoles are useful intermediate, for example, in [2+4] cycloaddition chemistry. 